\title{
Memory transfer for emotionally valenced words between identities in dissociative identity disorder.
}

Citation for published version (APA):

Huntjens, R. J. C., Peters, M. L., Woertman, L., van der Hart, O., \& Postma, A. (2007). Memory transfer for emotionally valenced words between identities in dissociative identity disorder. Behaviour Research and Therapy, 45, 775-789. https://doi.org/10.1016/j.brat.2006.07.001

Document status and date:

Published: 01/01/2007

DOI:

10.1016/j.brat.2006.07.001

Document Version:

Publisher's PDF, also known as Version of record

Document license:

Taverne

Please check the document version of this publication:

- A submitted manuscript is the version of the article upon submission and before peer-review. There can be important differences between the submitted version and the official published version of record.

People interested in the research are advised to contact the author for the final version of the publication, or visit the DOI to the publisher's website.

- The final author version and the galley proof are versions of the publication after peer review.

- The final published version features the final layout of the paper including the volume, issue and page numbers.

Link to publication

\footnotetext{
General rights rights.

- You may freely distribute the URL identifying the publication in the public portal. please follow below link for the End User Agreement:

www.umlib.nl/taverne-license

Take down policy

If you believe that this document breaches copyright please contact us at:

repository@maastrichtuniversity.nl

providing details and we will investigate your claim.
}

Copyright and moral rights for the publications made accessible in the public portal are retained by the authors and/or other copyright owners and it is a condition of accessing publications that users recognise and abide by the legal requirements associated with these

- Users may download and print one copy of any publication from the public portal for the purpose of private study or research.

- You may not further distribute the material or use it for any profit-making activity or commercial gain

If the publication is distributed under the terms of Article $25 \mathrm{fa}$ of the Dutch Copyright Act, indicated by the "Taverne" license above, 


\title{
Memory transfer for emotionally valenced words between identities in dissociative identity disorder
}

\author{
Rafaële J.C. Huntjens ${ }^{\mathrm{a}, *}$, Madelon L. Peters ${ }^{\mathrm{b}}$, Liesbeth Woertman ${ }^{\mathrm{c}}$, \\ Onno van der Hart ${ }^{\mathrm{c}}$, Albert Postma ${ }^{\mathrm{d}}$ \\ ${ }^{a}$ University of Groningen, Department of Developmental and Clinical Psychology, Groningen, The Netherlands \\ ${ }^{\mathrm{b}}$ Maastricht University, Department of Clinical, Medical, and Experimental Psychology, Maastricht, The Netherlands \\ ${ }^{\mathrm{c}}$ Utrecht University, Department of Clinical Psychology, Utrecht, The Netherlands \\ ${ }^{\mathrm{d}}$ Utrecht University, Psychological Laboratory, Utrecht, The Netherlands
}

Received 18 November 2005; received in revised form 22 June 2006; accepted 3 July 2006

\begin{abstract}
The present study aimed to determine interidentity retrieval of emotionally valenced words in dissociative identity disorder (DID). Twenty-two DID patients participated together with 25 normal controls and 25 controls instructed to simulate DID. Two wordlists A and B were constructed including neutral, positive and negative material. List A was shown to one identity, while list B was shown to another identity claiming total amnesia for the words learned by the first identity. The identity claiming amnesia was tested for intrusions from list A words into the recall of words from list B and recognition of the words learned by both identities. Test results indicated no evidence of total interidentity amnesia for emotionally valenced material in DID. It is argued that dissociative amnesia in DID may more adequately be described as a disturbance in meta-memory functioning instead of an actual retrieval inability.
\end{abstract}

(C) 2006 Elsevier Ltd. All rights reserved.

Keywords: Dissociative identity disorder; Amnesia; Multiple personality disorder

\section{Introduction}

Dissociative amnesia is a major symptom of dissociative identity disorder (DID). In the fourth edition of the Diagnostic and Statistical Manual of Mental Disorders, dissociative amnesia is described as the "inability to recall important personal information that is too extensive to be explained by ordinary forgetfulness" (American Psychiatric Association, 1994, p. 477). The DID patient's reported inability to recall information is predominantly thought to derive from the compartmentalization of memories in separate identity states. The assumed function of this compartmentalization is to reduce the effects of exposure to severely aversive stimuli, as well as to minimize the impact of these traumata on daily life (Cardeña, 1994; Dorahy, 2001). The diagnosis of DID has always been plagued by questions regarding the authenticity of the disorder (Allen \& Movius,

\footnotetext{
*Corresponding author. Tel.: + 31302531632 ; fax + 31302534718 .

E-mail address: R.Huntjens@fss.uu.nl (R.J.C. Huntjens).
} 
2000). There has been speculation that DID is a syndrome of role enactment developed by social creation or iatrogenesis in the treatment of suggestible individuals. This role enactment is carried out in a seemingly spontaneous fashion and with a high degree of involvement, such that the role and the self become indistinguishable for the subject (Dick-Barnes, Nelson, \& Aine, 1987; Lilienfeld et al., 1999; Spanos, 1996).

Unfortunately, the number of experimental studies on amnesic barriers between identities is limited, and the samples of patients included usually very small. The older studies typically were case studies (Dick-Barnes et al., 1987; Ludwig, Brandsma, Wilbur, Benfeldt, \& Jameson, 1972; Nissen, Ross, Willingham, Mackenzie, \& Schacter, 1988) Later studies have included more patients. Interidentity amnesia was assessed by having one identity learn a set of stimuli and testing another identity (self-reporting amnesia for the stimulus material) for retrieval ability. Eich, Macaulay, Loewenstein, and Dihle (1997a, 1997b; $n=9$ ) found evidence of amnesia when patients were explicitly asked to recall what the other identity had learned. Also, evidence of amnesia of information was found on an implicit measure (word-stem completion task) that permitted a wide range of responses whose selection may have varied from one identity to the next and evidence of transfer was found on an implicit measure that left little room for identity-specific interpretation and allowed for only one correct response (picture-fragment completion). Peters, Uyterlinde, Consemulder, and Van der Hart $(1998 ; \mathrm{n}=4)$ found evidence for amnesia both on explicit memory tests and an implicit test (word-stem completion), although one of the participants showed some evidence of leakage of information between identity states. In the explicit memory test, patients were informed in the test phase that the other identity had learned a number of words that she should try to recall. The word-stem completion task allowed for a range of responses.

To investigate claims of interidentity amnesia in DID it seems important to rule out an alternative hypothesis of simulation of interidentity amnesia. It can be argued that simulation of amnesia was easy particularly on the tasks described above that explicitly ask the patient to recall material learned by another identity and on tasks that allow for a wide range of responses (i.e., in order to feign amnesia, one can simply select a different answer). Note in this regard that Nissen et al. (1988) stated "we found that in this patient, as in most other patients with multiple personality disorder, one personality was unable or unwilling (emphasis added) to explicitly recall or recognize stimuli presented to another identity"(p. 130). A way of checking the possibility of simulation is to include DID-simulators in the study. Unfortunately, Peters et al. (1998) did not include DID simulators. Eich et al. (1997a, 1997b) only tested DID-simulators in the picture-fragment completion task (with results indicating interidentity transfer), and not in the word stem-completion task (with results of interidentity amnesia). None of the case studies included a simulator group.

To take into account the possibility of amnesia-simulation, more ingenious memory measures and paradigms have been employed in recent studies of interidentity amnesia in DID, as well as specifically instructed groups of simulators. In a study by Huntjens et al. $(2002 ; n=31)$, several implicit memory tests were included, both tests on which a specific response was required and tasks that permitted a wide range of responses. To decrease the possibility of simulation of interidentity amnesia, a large interval between the learning phase and the test phase was used (e.g., in order to reduce conscious knowledge of stimulus material), and tasks were used that require a speeded response (e.g., it was supposed this would make it more difficult to strategically influence responses compared to a non-speeded instruction). The results indicated that DID simulators were unable to simulate amnesia. The results for the patients indicated, in contrast to previous results, evidence of transfer of information between identities on all the implicit measures employed.

Patients were also found to be able to consciously retrieve material learned in another identity state when using a so-called interference paradigm used by Silberman, Putnam, Weingartner, Braun, and Post (1985; $n=9)$ ) and Huntjens, Postma, Peters, Woertman, and Van der Hart (2003). In this paradigm, two highly confusable sets of stimuli (e.g., words from the same semantic categories) were used, and each set was learned by a different identity. After a time interval, the amnesic identity was tested for knowledge of both sets of stimuli. This identity was hypothesized to be better at discriminating between the stimulus sets compared to normal controls, for whom the first set of stimuli interfered with the learning of the second set. Simulation was supposed to be difficult given participants were supposed to be unable to stop the interference of the highly related materials. As it turned out, simulators indeed were unable to simulate interidentity amnesia, that is, they had as much problems as normal controls with discriminating the material from both lists. The results of the patients indicated they consciously recalled and recognized the words learned by another identity. The transfer of information on explicit retrieval tasks found in these studies coincide with the results of a study of 
Allen and Movius (2000; $n=4)$, who used a recognition task combined with event-related potential measures to index interidentity memory performance. Although not completely consistent, the results indicated recognition of material learned both in the same and another identity state.

It can be concluded that in the latter studies no evidence of interidentity amnesia was found, neither for explicit nor implicit memory retrieval of events experienced by another identity. Importantly, however, the studies discussed made use of neutral stimulus material. Given the high prevalence of a history of trauma, more specifically of sexual and physical abuse, in patients with DID and other dissociative patients that report amnesia (Lewis, Yeager, Swica, Pincus, \& Lewis, 1997; Ogawa, Sroufe, Weinfield, Carlson, \& Egeland, 1997; Putnam, Guroff, Silberman, Barban, \& Post, 1986), and the supposed function of amnesic barriers between identity states to ward off painful memories, it may be hypothesized that interidentity amnesia in DID is limited to trauma-related material (Dorahy, 2001; Peters et al., 1998; Putnam, 1995). Accordingly, the DSMIV definition of amnesia emphasizes the inability to recall important personal information.

In line with the DSM-IV definition of dissociative amnesia and the high prevalence of history of trauma in dissociative patients, the purpose of the present study was to test explicit retrieval of emotionally valenced material between identity states in DID. Twenty-two DID patients were included, as well as a normal control group and a control group instructed to simulate DID. An interference task was used, with two wordlists $\mathrm{A}$ and $\mathrm{B}$ that were composed of negative words, positive words, and neutral words. The negative words were chosen to reflect physical and sexual childhood abuse. Neutral words were added as a baseline measure and positive words to control for the general effect of emotional valence. The words of both lists were chosen to be similar both in conceptual meaning (e.g., "throat" and "swallow"), and other details like first letter of the words (e.g., "penis" and "pain"). List A was shown to one identity, and the identity was asked to recall the list A words. List B was shown to another identity claiming total amnesia for the events experienced by the first participating identity during the experiment. This identity was asked to recall the list B words. The first memory measure consisted of testing the identity claiming amnesia for intrusions from list A words into the recall of words from list B. Secondly, the amnesic identity was also tested for recognition and list assignment (i.e., assigning recognized words to either list $\mathrm{A}$ or list $\mathrm{B}$ ) of material learned by both identities. If DID involves dissociation of emotionally loaded information, interidentity amnesia would be expected for the negative words. Thus, patients were expected to recall no or fewer list A negative word intrusions during the recall of list B. Furthermore, they were hypothesized to recognize fewer negative list A words (learned in another identity state) in comparison with list B words (learned in the same identity state) and also be worse in list A assignment of words compared to list B.

Cardeña (2000) mentioned that in case of coconsciousness between identities, DID patients may recollect an event experienced by another identity as if the patient had watched it rather than experienced it (i.e., an "impersonal" recollection). To provide information on this qualitative aspect of remembering in DID, we added a procedure assessing the state of awareness during recognition. The state of awareness can be characterized as either remembering or knowing. Remembering is a recollective experience based on associative, contextual information of the learning event. Knowing is retrieval by a feeling of familiarity without specific knowledge of the original event (Gardiner \& Java, 1993; Knowlton, 1998; Knowlton \& Squire, 1995; Tulving, 1985), (i.e., resembling the impersonal recollection as suggested by Cardeña (2000)). Following recognition, participants had to state if their recognition was a remember or a know recognition. We hypothesized patients to characterize material learned in the other identity state more as knowing and material learned in the same identity state more as remembering.

\section{Method}

\section{Participants}

Twenty-two female DID patients participated. They were recruited from 18 treatment settings in the Netherlands and Belgium by asking clinicians to invite patients to participate. Nine patients also had participated in our previous experiments of interidentity amnesia (Huntjens et al., 2002, 2003). Before the experiment, therapists were asked to confirm patients met the conditions for participation, that were described as follows: (1) The DID diagnosis was made by the referring clinician by administration of the Structured 
Clinical Interview for DSM-IV Dissociative Disorders (SCID-D; Steinberg, 1993; Dutch version validated by Boon \& Draijer, 1993); (2) at least one of the identities was completely amnesic for the events experienced by the other participating identity during the experiment; (3) identities are able to perform the tasks without interference of other identities; (4) they are able to perform the tasks without spontaneous switches to other identities; and (5) they are all able to switch between identities on request. The mean number of years since diagnosis of DID for patients in the present sample was 6 years and DID was always the main reason for patients to be in treatment.

Patients were informed that the aim of the study was to understand more about the memory problems often reported by patients with DID. They self-selected two identities that would participate in the experiment. As mentioned in the conditions for participation, patients in this study were able to switch between the two participating identities on request, and were able to perform the tasks without spontaneous switches to other identities. The transition was initiated by asking the patient to let an identity "come forward" and take control over the patient's consciousness and behavior. Also, the patient was asked to let the other participating identity "step back", thereby moving out of consciousness. The switching process was assisted by the patients' own clinician (and in three cases by one of the authors, RH). The clinician paid attention that no spontaneous switches to other identities occurred during the learning and testing phase. As a second verification, it was regularly checked with the patient that the identity present performed the task without interference of other identities.

In addition, 50 female non-psychiatric control participants were recruited. They were community volunteers and received a small payment. They did not report any relevant memory, visual, attentional problems or psychiatric disorders, and no history of sexual abuse when explicitly asked to report any of these difficulties. Control participants were assigned randomly to either a control group or a simulating group. Groups were matched as closely as possible on age $(M=39.95, S D=8.81$ for patients $[n=22] ; M=37.40, S D=8.00$ for normal controls; and $M=36.72, S D=7.88$ for simulators) and education ${ }^{1}(M=5.36, S D=1.59$ for patients $[n=22] ; M=5.72, S D=1.14$ for normal controls, and $M=5.68, S D=1.18$ for simulators). Participants in the simulating group were instructed to mimic DID. They were shown a documentary about a DID-patient and were given additional written information about DID. The documentary depicted a female patient talking about her experience of having DID and more specifically about experiences of dissociative amnesia. For example, she shows her diary in which several identities have written in different handwriting and explains she has asked her identities to write down where she has been. The written information provided further details on DID (e.g., a summary of the DSM criteria) and explained what would be required of them during the experiment and how they should prepare for the switching to their imagined identity. They were subsequently asked to make up an imaginary, amnesic identity and come up with detailed characteristics of this identity. Following Silberman et al.'s (1985) procedure, they were given a 17-item data sheet for the identity on which they were asked to assign name, age, sex, physical description, personal history, and personality style. Examination of the completed data sheets confirmed that participants had spent considerable effort inventing an identity, that is, they answered all the questions in detail. Finally, they were asked to practice during the week preceding the test in switching to their "identity" and taking on its state of mind. Participants in the normal control group were only told that they participated in a memory experiment. No information was provided on the DID-related aspects of the study.

All participants completed both the Dissociative Experiences Scale (DES; Carlson \& Putnam, 1993) and the Creative Experience Questionnaire (CEQ; Merckelbach, Rassin, \& Muris, 2000). The DES is a 28-item selfreport questionnaire with scores ranging from 0 to 100 . Scores above 20, or more conservatively, above 30 are thought to be indicative of pathological dissociation (Carlson \& Putnam, 1993). The CEQ is a Dutch 25-item self-report questionnaire with scores ranging from 0 to 25 . High scores are thought to be indicative of "fantasy proneness", i.e., the inclination to be immersed in daydreams and fantasies. Mean scores on the DES were $M=52.19(S D=16.41)$ for patients, $M=9.61(S D=8.20)$ for normal controls, and $M=8.11(S D=4.71)$ for simulators. Scores on the CEQ were $M=9.70(S D=4.50)$ for patients, $M=6.32(S D=3.22)$ for normal controls, and $M=6.64(S D=4.02)$ for simulators. Control participants did not show a pathological level of dissociation as measured by the DES. The normal control group and the simulating control group did not

\footnotetext{
${ }^{1}$ Education was assessed in categories ranging from 1 (low) to 7 (high) (Verhage, 1964).
} 
differ significantly on DES, $t(48)=.79, p=.43$, Cohen's $d=.22$. They also did not differ significantly on CEQ, $t(48)=-.31, p=.76$, Cohen's $d=.09$. Patients, on the other hand, differed significantly from normal controls both on the DES, $t(45)=11.46, p<.01$, Cohen's $d=.87$, and the CEQ, $t(45)=2.99, p<.01$, Cohen's $d=3.35$. Written informed consent was obtained from patients as well as all control participants prior to participation.

\section{Materials}

Two wordlists named A and B were constructed. List A and list B both contained eight different negative words with a threatening or sexual connotation such as "vagina" and "pain", eight positive words such as "music" and "blossom", and ih neutral words such as "branch" and "bag". Additionally, a recognition-list was developed including all the words from lists A and B and an equal amount of negative, positive, and neutral distractor words (new words) adding up to a total of 96 words. The words were selected by two of the authors ( $\mathrm{LW}$ and $\mathrm{OvdH})$, who as clinicians treat DID patients. Some words were selected from a study of Hermans and De Houwer (1994), in which 145 first year psychology students rated words for emotional valence. Other words were added on face value. The list A and B words and the distractor words were chosen to match as much as possible in conceptual meaning and first letter of the word. Word lists and word categories also did not differ significantly with respect to mean frequency of occurrence per million ${ }^{2}$ and mean word length. ${ }^{3}$ Furthermore, to ensure that participants' differences in recall could not be due to differences in list difficulty, a pilot study was performed, with 19 psychology students serving as participants. Students were randomly assigned to one of two groups and list order (AB or BA) was counterbalanced. The study showed no differences in recall between list orders $\mathrm{AB}$ and $\mathrm{BA}, F(1,17)=.30, p=.59$.

At the end of the session, participants rated all words on a paper-and-pencil version of the Self-Assessment Manikin (SAM; see Bradley, Greenwald, Petry, \& Lang, 1992), used to rate affective valence. The scale ranges from 1 (happy/positive) to 9 (unhappy/negative). Two patients did not complete the rating session, because the test session proved too long and taxing for them. Mean rating scores for controls were $M=6.90(S D=.89)$ for negative words, $M=2.82(S D=1.03)$ for positive words, and $M=4.46(S D=.71)$ for neutral words; mean scores for patients were $M=7.70(S D=.99)$ for negative words, $M=3.41(S D=.83)$ for positive words, and $M=4.49(S D=.47)$ for neutral words; mean scores for simulators were $M=6.97(S D=.61)$ for negative words, $M=2.69(S D=.54)$ for positive words, and $M=4.31(S D=.44)$ for neutral words. A repeated measures analysis of variance with Word Category [negative, positive, neutral] as the withinsubjects factor, and Diagnosis [patients, controls and simulators] as the between-subjects factor revealed a significant Word Category main effect, $F(2,66)=292.60, p<.01$. Negative words were rated more negatively than positive words, $p<.01$, and neutral words, $p<.01$. Positive words were rated more positively than neutral words, $p<.01$. Also, a significant Diagnosis main effect was found, $F(2,67)=11.58, p<.01$, with patients rating words more negatively than controls, $p<.01$, and simulators, $p=<.01$. Controls and simulators did not differ significantly, $p>.99$. Also, there was a significant Word Category $\times$ Diagnosis interaction, $F(4,134)=5.36, p<.01$, reflecting the patients negative ratings of negative words and positive words (but not neutral words) in comparison with controls and simulators.

\section{Procedure}

The study was part of a larger investigation on memory (dis)abilities in DID. The present study consisted of two sessions separated by a 2-h interval, during which participants performed several implicit memory tasks, on which we reported elsewhere (see Huntjens et al., 2005). There was no overlap in study material between these implicit memory tasks and the present task. The interval between sessions was used to prevent ceiling

\footnotetext{
${ }^{2} 37.38$ for negative words, List A; 39.00 for positive words, List A; 35.88 for neutral words, List A; 36.25 for negative words, List B; 40.88 for positive words, List B; 35.75 for neutral words, List B; 36.88 for negative words, Recognition-List; 33.75 for positive words, Recognition-List; 37.06 for neutral words, Recognition-List (CELEX, 1990).

${ }^{3} 6.00$ for negative words, List A; 5.63 for positive words, List A; 5.88 for neutral words, List A; 6.50 for negative words, List B; 6.38 for positive words, List B; 6.00 for neutral words, List B; 6.25 for negative words, Recognition-List; 6.25 for positive words, Recognition-List; 6.19 for neutral words, Recognition-List (CELEX, 1990).
} 
memory performance and to complicate list assignment. A $2 \mathrm{~h}$ interval was used instead of a week (the interval used in the interference task as reported in Huntjens et al., 2003) purely for practical reasons.

In Session 1, the 24 words of list A were presented once to the patient's identity 1 in random order on a computer screen for $2 \mathrm{~s}$ with a 2-s interval. The words were presented only once to avoid ceiling effects in recall and recognition. Before the presentation, participants were told that they should try to encode the words to the best of their ability in order to recall them subsequently. Following the presentation, participants were asked to write down as many words as possible of the studied words that they could recall. After this, patients were requested to switch to the amnesic identity 2 . When the patient confirmed the presence of identity 2 , this identity was asked whether the identity knew anything about the learning episode, that is, the procedure followed and/or the material studied. If patients indicated they had knowledge about the learning phase, they were asked to describe what they knew. Then, the words of list B were presented to identity 2 , and the participant was tested for free recall.

Then followed a 2-h interval, after which Session 2 took place in which identity 2 was tested for recognition. The recognition test had not been announced in Session 1. The words of the recognition-list were presented one at a time and the patients had to state whether they recognized the words as old (i.e., from Session 1). If they recognized a word, they additionally had to state if their recognition was a remember or a know recognition. Participants received extensive instructions about the remember and know responses resembling instructions described by Gardiner (1988) (see also Gardiner \& Parkin, 1990). Remember responses were described as recognition states in which you have a conscious recollection of some aspect of the original encounter with the particular item. Know responses just elicit a feeling of familiarity, without however remembering specific contextual elements (Postma, 1999).

After completion of the recognition test for all the words, list-assignment was determined. Identity 2 was informed that identity 1 had seen a different word list called list A. Then identity 2 was told that a new set of words would be shown and that each word originated from either their own list B or from list A seen by identity 1. Patients were asked to state for each word if it originated from their own list B. It was explained that if they had not seen the word, it originated from list A. However, the set of words that patients saw actually was not a new set of words from list A and B but they were the words patients previously had "recognized" (both correctly and incorrectly).

Participants in the simulating control group learned and were tested for list A while being in their normal identity state and list B after having switched to their imagined "amnesic" identity. The recognition and the assignment tasks also had to be performed by this imagined identity. Before "switching" to their other identity, they were instructed to pretend that they did not know their normal identity had seen a list called A and so they had no remembrance of the words and no practice in performing a memory task. It was made sure they fully understood the amnesia-instruction by asking them to repeat the instruction in their own words. Subsequently, they were given 2 min to take on the other identity's state of mind. Participants in the control group performed the task without switching. Instead, they had a 2-min break to keep the length of procedures equal between groups.

After the memory testing, the participants performed the valence-rating task, and subsequently completed the questionnaires. Simulators completed both parts in their normal state, i.e., not simulating dissociative amnesia.

\section{Results}

Despite claims of interidentity amnesia at the start of the study, three patients reported knowledge of some sort of the learning phase when asked directly after their switch to identity 2 . One patient reported knowledge of a single word and a second patient reported knowledge of two words. The third patient reported knowledge of the procedure, while denying knowledge of the material itself. Patients did not claim that they were directly aware of the other identity's doings. They claimed the knowledge was told to them "as a voice in their head" or by a third identity. The data of the three patients were excluded from the results. The data thus pertain to 19 DID patients who subjectively reported complete one-way amnesia in the test phase for the learning phase including the words presented in list A. 
Effect sizes reported are partial $\eta^{2}$. All multiple comparisons procedures described were Bonferroni tests. Given an alpha level of .05 and total sample size of 69 , the power of $F$-tests to detect large effect sizes in this study was .84 , the power to detect medium effect sizes was .43 , and the power to detect small effect sizes was .10. Following Stevens (1996), we adjusting the alpha to .15 to increase the power, resulting in a power of .91 to detect large effect sizes, .56 to detect medium effect sizes, and .18 to detect small effect sizes (power statistics calculated with the program GPower, see Erdfelder, Faul, \& Buchner, 1996).

\section{Recall}

Recall scores are presented to give an account of the participants' overall memory performance. Mean numbers of recalled negative, positive, and neutral words of list A and list B for patients, controls, and simulating controls are presented in Table 1. Analysis was accomplished by repeated measures analysis of variance with List [list A, list B], and Word Category [negative, positive, neutral] as within-subjects factors, and Diagnosis [patients, controls and simulators] as a between-subjects factor. A significant List main effect was found $F(1,66)=13.85, p<.01$, partial $\eta^{2}=.17$, and a significant List $\times$ Diagnosis interaction, $F(2,66)=7.59, p<.01$, partial $\eta^{2}=.19$, indicating patients and simulators showed decreased recall scores in their (imagined) amnesic identity, compared to their non-amnesic identity and compared to controls, who showed comparable list A and B recall scores. Also, a significant Word Category main effect was found, $F(2,65)=43.28, p<.01$, partial $\eta^{2}=.57$. Participants recalled significantly more negative words than positive words, $p<.01$, and significantly more negative words than neutral words, $p<.01$. Positive words were not recalled significantly more than neutral words, $p=.33$. The Word Category $\times$ Diagnosis interaction proved not significant, $F(4,132)=.89, p=.47$, partial $\eta^{2}=.03$, as did the List $\times$ Word Category $\times$ Diagnosis interaction, $F(4,132)=.52, p=.72$, partial $\eta^{2}=.02$, indicating that all participants, and not specifically DID patients, recalled more negative words compared to positive and neutral words. Finally, a main effect of Diagnosis was observed, $F(2,66)=5.33, p=.01$, partial $\eta^{2}=.14$. A multiple comparisons procedure showed that patients demonstrated a significantly overall lower recall than controls, $p=.01$, and simulators, $p=.06$ (i.e., using the more lenient alpha as described above), while simulators clearly did not differ from normal controls in overall recall, $p>.99$. All other effects were not significant.

\section{Intrusions}

Seven patients recalled one or more intrusions from list A when recalling words from list B, compared to 10 controls and seven simulators. More specifically, three patients compared to three controls and three simulators recalled a negative word intrusion from list A when recalling words from list B. One-sample $t$-tests indicated mean intrusions differed significantly from zero, $t(68)=3.19, p<.01$ for negative intrusions, $t(68)=3.94, p<.01$ for positive intrusions, and $t(68)=2.55, p=.01$ for neutral intrusions. A Pearson $\chi^{2}$-test showed that diagnosis groups did not differ significantly in the distribution of participants making one or more intrusion errors and participants making no intrusion errors, $\chi^{2}(2, N=69)=.84, p=.66$.

Table 1

List-dependent recall for negative, positive, and neutral words for DID patients $(n=19)$, controls $(n=25)$, and simulators $(n=25)$

\begin{tabular}{lccc}
\hline & DID patients & Controls & Simulators \\
\hline List $A$ & & & $5.12(1.17)$ \\
Negative words & $4.47(1.26)$ & $3.40(1.78)$ & $5.00(1.32)$ \\
Positive words & $2.68(1.83)$ & $3.08(1.47)$ & $4.12(1.69)$ \\
Neutral words & $2.63(1.42)$ & & $3.44(1.47)$ \\
List $B$ & $3.79(2.15)$ & $4.48(1.83)$ & $3.92(1.53)$ \\
Negative words & $2.16(1.07)$ & $3.68(1.44)$ & $2.96(1.49)$ \\
Positive words & $2.53(1.61)$ & $3.72(1.46)$ & $2.68(1.52)$ \\
Neutral words & & & \\
\hline
\end{tabular}

Note: List A words were learned by the patients' first identity, and list B by the patients' second identity. 


\section{Recognition}

List-dependent recognition hit rates were determined for list $\mathrm{A}$ and list $\mathrm{B}$, and a false alarm rate (see Table 2). Patients recognized $38 \%$ of the negative words learned by the other identity, compared to $54 \%$ of the negative words learned in the same identity state. They also recalled $31 \%$ of the positive words and $30 \%$ of the neutral words learned by the other identity, compared to $42 \%$ of the positive and neutral words learned in the same identity state.

List-dependent measures of sensitivity (see Table 3) were calculated from $z$-scores, as described by MacMillan and Creelman (1991). Sensitivity is expressed in the measure of $d$ ' and includes the number of targets (old words recognized as old) while correcting for the number of distractor words falsely recognized. When observers cannot discriminate at all (the hit rate equals the false alarm rate), $d^{\prime}=0$. Moderate performance implies that $d$ ' is near unity. Perfect accuracy (all responses are hits or correct rejections), implies an infinite $d$. A repeated measures analysis on the recognition sensitivity scores showed a significant List

Table 2

List-dependent recognition hit rates and false alarm rate for negative, positive, and neutral words for DID patients $(n=19)$, controls $(n=25)$, and simulators $(n=25)$

\begin{tabular}{llll}
\hline & DID patients & Controls & Simulators \\
\hline Hit rate list $A$ & & & $.73(.22)$ \\
Negative & $.38(.32)$ & $.68(.17)$ & $.45(.31)$ \\
Positive & $.31(.23)$ & $.62(.21)$ & $.38(.28)$ \\
Neutral & $.30(.25)$ & & $.36(.24)$ \\
Hit rate list $B$ & & $.72(.20)$ & $.62(.24)$ \\
Negative & $.54(.30)$ & $.72(.18)$ & $.57(.22)$ \\
Positive & $.42(.23)$ & $.72(.20)$ & $.50(.24)$ \\
Neutral & $.42(.23)$ & & $.06(.08)$ \\
False alarm rate & & $.12(.18)$ & $.05(.07)$ \\
Negative & $.12(.19)$ & $.11(.12)$ & $.05(.08)$ \\
Positive & $.08(.14)$ & $.13)$ & \\
Neutral & $.08(.14)$ & & \\
\hline
\end{tabular}

Note: List A words were learned by the patients' first identity, and list B by the patients' second identity. All data were provided by testing the second identity.

Table 3

List-dependent recognition sensitivity and overall response bias for negative, positive, and neutral words for DID patients $(n=19)$, controls $(n=25)$, and simulators $(n=25)$

\begin{tabular}{llll}
\hline & DID patients & Controls & Simulators \\
\hline $\begin{array}{l}\text { Sensitivity list } A \\
\text { Negative }\end{array}$ & $1.03(.90)$ & $2.42(1.14)$ & $1.58(1.00)$ \\
Positive & $1.00(1.00)$ & $2.03(.90)$ & $1.53(.89)$ \\
Neutral & $1.06(.93)$ & $1.75(.98)$ & $1.63(.66)$ \\
Sensitivity list $B$ & & & $2.24(.94)$ \\
Negative & $1.81(1.27)$ & $2.29(1.04)$ & $2.20(.70)$ \\
Positive & $1.51(.89)$ & $2.23(1.15)$ & $2.00(.78)$ \\
Neutral & $1.62(.92)$ & $2.08(1.00)$ & $.72(.48)$ \\
Response bias & & & $.85(.45)$ \\
Negative & $.75(.71)$ & $.33(.47)$ & $.91(.42)$ \\
Positive & $.98(.51)$ & $.36(.35)$ & \\
Neutral & $.97(.52)$ & $.32)$ & \\
\hline
\end{tabular}

Note: List A words were learned by the patients' first identity, and list B by the patients' second identity. All data were provided by testing the second identity. 
effect, $F(1,66)=32.89, p<.01$, partial $\eta^{2}=.33$, with sensitivities being the highest for list B. Also, a significant List $\times$ Diagnosis interaction was found, $F(2,66)=4.17, p=.02$, partial $\eta^{2}=.11$, reflecting only patients and simulators showed an increase in sensitivity between lists. In a separate analysis including only normal controls, the List main effect proved not significant, $F(1,24)=1.74, p=.20$, partial $\eta^{2}=.07$. A separate analysis including only patients and simulators showed they did not differ significantly in list sensitivity increase, $F(1,42)=.06, p=.81$, partial $\eta^{2}<.01$. Importantly, the List $\times$ Word Category $\times$ Diagnosis interaction was not significant, $F(4,132)=1.62, p=.17$, partial $\eta^{2}=.05$, indicating the increase in sensitivity between lists for patients and simulators was not specific for negative words. Finally, a significant Diagnosis effect was found, $F(2,66)=8.61, p<.01$, partial $\eta^{2}=.21$, with patients scoring significantly lower than controls, $p<.01$, and simulators, $p=.03$, in overall sensitivity. Simulators did not differ significantly from controls, $p=.41$. All other recognition sensitivity effects were not significant.

Response bias is expressed in the measure of $C$ and refers to the tendency to favor "old" or "new" responses. A response bias score of 0 indicates a neutral response tendency. Positive scores reflect a conservative response bias, i.e., often assigning a "new" status to both words seen and distractors. Negative scores reflect a liberal response bias, i.e., often assigning an "old" status to both words seen and distractors. On overall response bias (see Table 3 ), there was a significant Word Category main effect, $F(2,65)=3.73$, $p=.03$, partial $\eta^{2}=.10$. Within-subjects contrasts revealed that the negative words response bias was more liberal than the positive words response bias, $p=.02$, and the neutral words response bias, $p=.01$, indicating participants more readily accepted negative words as "old" compared to positive and neutral words. The positive words response bias did not differ significantly from the neutral words response bias, $p=.58$. This Word Category main effect did not differ between Diagnosis Groups, $F(4,132)=.64, p=.63$, partial $\eta^{2}=.02$. Finally, there was a significant Diagnosis Group main effect, $F(2,66)=12.23, p<.01$, partial $\eta^{2}=.27$. A multiple comparison procedure revealed that patients as well as simulators scored significantly more conservative than normal controls, $p<.01$ for both comparisons, indicating that both groups were more inclined to classify items as "old" than "new". Patients did not differ significantly from simulators, $p=1.00$.

\section{List assignment}

The assignment hit rates were calculated separately for each word category and each list as the number of words correctly assigned to a list divided by the number of list items recognized. Assignment false alarm rates were calculated by dividing the number of words wrongly assigned to a list, be it either distractors or words from the other list, divided by the number of distractors "recognized" and the number of other list items "recognized". Assignment sensitivity and response bias are presented in Table 4 and were calculated as described by MacMillan and Creelman (1991).

On assignment sensitivity, a significant List effect, $F(1,66)=37.91, p<.01$, partial $\eta^{2}=.37$, and a significant List $\times$ Diagnosis interaction was found, $F(2,66)=14.83, p<.01$, partial $\eta^{2}=.31$, reflecting an increase in list assignment sensitivity (with list B assignment sensitivity being the highest) for patients and simulators but not for controls. ${ }^{4,5}$ A separate analysis only including patients and simulators showed they differed significantly in sensitivity increase between lists, $F(1,42)=8.26, p<.01$, partial $\eta^{2}=.16$, with patients showing a bigger increase between lists (i.e., both groups having equivalent list B assignment sensitivities, but patients having a decreased list A assignment sensitivity). Patients thus were better able to assign words learned in the same identity to the correct list than words learned in the other identity. As can be seen in Table 4, patients even had negative list A assignment sensitivity scores, reflecting very low hit rates (in combination with relatively high false alarm rates). This pattern of results was also shown, but to a lesser degree, by simulators. The pattern was not different for the word categories, as indicated by the not significant List $\times$ Word Category $\times$ Diagnosis interaction, $F(4,132)=.88, p=.48$, partial $\eta^{2}=.03$. We did find a significant Word Category main effect, $F(2,65)=2.74, p=.07$ (i.e., using the more lenient alpha as described

\footnotetext{
${ }^{4}$ In a separate analysis only including normal controls, the List increase was not significant, $F<1$.

${ }^{5} \mathrm{~A}$ separate analysis excluding patients indicated simulators differed significantly from normal controls, $F(1,48)=10.52, p<.01$, partial $\eta^{2}=.18$.
} 
Table 4

List-dependent assignment sensitivity and response bias for negative, positive, and neutral words for DID patients $(n=19)$, controls $(n=25)$, and simulators $(n=25)$

\begin{tabular}{|c|c|c|c|}
\hline & DID patients & Controls & Simulators \\
\hline \multicolumn{4}{|c|}{ Sensitivity list $A$} \\
\hline Negative & $-.48(1.67)$ & $1.13(1.58)$ & $.92(1.99)$ \\
\hline Positive & $-.55(1.71)$ & $.51(1.35)$ & $.41(2.35)$ \\
\hline Neutral & $.20(1.82)$ & $1.22(1.52)$ & $.98(2.14)$ \\
\hline \multicolumn{4}{|c|}{ Sensitivity list $B$} \\
\hline Negative & $1.23(1.62)$ & $.97(1.64)$ & $1.74(2.15)$ \\
\hline Positive & $.76(2.26)$ & $.66(1.32)$ & $1.14(2.02)$ \\
\hline Neutral & $1.74(2.50)$ & $1.22(1.46)$ & $1.07(2.03)$ \\
\hline \multicolumn{4}{|c|}{ Response bias list $A$} \\
\hline Negative & $.87(1.36)$ & $-.16(.74)$ & $.84(1.15)$ \\
\hline Positive & $.84(.95)$ & $.11(.74)$ & $.31(1.20)$ \\
\hline Neutral & $.82(1.12)$ & $.04(.74)$ & $.53(1.25)$ \\
\hline \multicolumn{4}{|c|}{ Response bias list $B$} \\
\hline Negative & $-.11(1.48)$ & $.01(.77)$ & $-.61(1.06)$ \\
\hline Positive & $-.20(1.16)$ & $-.16(.70)$ & $-.04(1.29)$ \\
\hline Neutral & $-.48(.85)$ & $-.29(.60)$ & $-.54(1.23)$ \\
\hline
\end{tabular}

Note: List A words were learned by the patients' first identity, and list B by the patients' second identity. All data were provided by testing the second identity.

above), partial $\eta^{2}=.08$, with assignment sensitivity being lower for positive words compared to neutral words, $p=.03$. All other effects were not significant.

A negative response bias indicates a liberal assignment bias, i.e., a tendency to assign words to a certain list. A positive response bias indicates a conservative response bias, i.e., an inclination not to assign words to the list. We found a significant List main effect, $F(1,66)=26.18, p<.01$, partial $\eta^{2}=.28$, and a significant List $\times$ Diagnosis interaction, $F(2,66)=4.45, p=.02$, partial $\eta^{2}=.12$, reflecting a more conservative patient and simulator list A response bias compared to list B (see footnote 4). A separate analysis excluding normal controls showed patients and simulators did not differ significantly in response bias differences between lists, $F(1,42)=.12, p=.74$, partial $\eta^{2}<.01$. Patients thus were more conservative in assigning words to list $\mathrm{A}$ than to list B. Simulators also showed this pattern of results, however. The pattern of response bias was not different for different word categories, as indicated by the not significant List $\times$ Word Category $\times$ Diagnosis interaction, $F(4,132)=.94, p=.44$, partial $\eta^{2}=.03$. We did find a significant Diagnosis main effect, $F(2$, $66)=10.63, p<.01$, partial $\eta^{2}=.24$, with patients overall being more conservative in list assignment than normal controls, $p<.01$, and simulators, $p=.03$. All other effects were not significant.

\section{Remember and know responses}

The remember and know rate for each list was determined as the number of words correctly recognized and assigned either a remember or know quality divided by the total number of list items. The mean proportions remember and know responses are presented in Table 5.

As can be seen in Table 5, controls characterized their recognitions on both lists more as remembering. In contrast, both patients and simulators characterized their recognitions from their own list (list B) more as remembering, while they characterized their recognitions from the list learned by the other identity (list A) more as knowing. This difference however, reflected in the interaction List $\times$ Quality (remember versus know) $\times$ Diagnosis, proved not significant, $F(2,66)=.93, p=.40$, partial $\eta^{2}=.03$. We thus did not find a significant difference between diagnosis groups in remember and know responses for information learned in the same versus other identity. More importantly for the question of state of awareness during recognition of negative material, the interaction Word Category $\times$ Quality $\times$ Diagnosis also proved not significant, 
Table 5

Proportions remember and know responses for negative, positive, and neutral words for DID patients $(n=19)$, controls $(n=25)$, and simulators $(n=25)$

\begin{tabular}{|c|c|c|c|}
\hline DID patients & Controls & Simulators & \\
\hline \multicolumn{4}{|c|}{ Remember list $A$} \\
\hline Negative & $.20(.28)$ & $.41(.27)$ & $.22(.22)$ \\
\hline Positive & $.14(.14)$ & $.38(.25)$ & $.16(.21)$ \\
\hline Neutral & $.09(.14)$ & $.34(.24)$ & $.10(.13)$ \\
\hline \multicolumn{4}{|l|}{ Know list $A$} \\
\hline Negative & $.17(.24)$ & $.32(.23)$ & $.23(.24)$ \\
\hline Positive & $.17(.15)$ & $.30(.20)$ & $.22(.26)$ \\
\hline Neutral & $.21(.17)$ & $.28(.21)$ & $.26(.24)$ \\
\hline \multicolumn{4}{|c|}{ Remember list $B$} \\
\hline Negative & $.31(.27)$ & $.40(.24)$ & $.41(.23)$ \\
\hline Positive & $.22(.16)$ & $.45(.26)$ & $.29(.23)$ \\
\hline Neutral & $.24(.21)$ & $.43(.27)$ & $.24(.21)$ \\
\hline \multicolumn{4}{|l|}{ Know list $B$} \\
\hline Negative & $.23(.17)$ & $.32(.24)$ & $.21(.24)$ \\
\hline Positive & $.20(.19)$ & $.27(.18)$ & $.28(.26)$ \\
\hline Neutral & $.18(.13)$ & $.30(.24)$ & $.27(.23)$ \\
\hline
\end{tabular}

Note: List A words were learned by the patients' first identity, and list B by the patients' second identity. All data were provided by testing the second identity.

$F(4,132)=1.22, p=.31$, partial $\eta^{2}=.04$. The interaction List $\times$ Word Category $\times$ Quality $\times$ Diagnosis also was not significant, $F(4,132)=1.49, p=.21$, partial $\eta^{2}=.04$, indicating that the differences in states of awareness during list recognition between controls on the one hand and patients and simulating controls on the other hand, did not differ for negative, positive, and neutral words. We did find a significant List $\times$ Quality interaction, $F(1,66)=11.06, p<.01$, partial $\eta^{2}=.14$, indicating participants qualified more list A words as know and more list B (being the last list to be learned) words as remember. Also, a significant Word Category $\times$ Quality interaction was found, $F(2,65)=2.39, p=.10$ (i.e., using the more lenient alpha as described above), partial $\eta^{2}=.07$, reflecting more remember responses for negative and positive words and more know responses for neutral words.

\section{Discussion}

The objective of this study was to investigate interidentity explicit memory retrieval for emotionally valenced material in DID. We hypothesized that there might exist a material-selective interidentity amnesia, with patients having difficulties remembering negatively valenced material learned in another identity state. As a first indicator of interidentity amnesia, patients were expected to recall no or fewer negative list A word intrusions during the recall of list B compared to controls. We found that patients did show intrusions. The number of patients recalling negative word intrusions was equal to the number of normal controls recalling negative word intrusions. Across word categories, mean intrusions differed significantly from zero for all diagnosis groups (i.e., patients, normal controls and simulators), while no significant differences between groups were found.

A second indicator for interidentity amnesia was the recognition measure. In case of interidentity amnesia, we expected patients to recognize fewer negative list A words (learned in another identity state) compared to list B words (learned in the same identity state). Importantly, the patients' mean list A recognition hit rate for negative words was not $0 \%$, as would be expected if patients were completely amnesic for negative words. They were found to recognize $38 \%$ of the list A negative words (learned by the other identity), compared to $54 \%$ of negative words learned in the same identity state (a relative increase of $42 \%$ ). They further recognized $31 \%$ of the positive list A words and $30 \%$ of the neutral list A words compared to $42 \%$ positive and neutral 
list B words. Patients thus recognized a considerable amount of words learned by the other identity, which argues against a hypothesis of complete interidentity amnesia. Patients did recognize significantly fewer list A words than list B words. The difference between groups in recognition sensitivity between lists was found, however, not to differ across word categories, and thus was not specific for negative words. On list assignment, patients were better able to assign words learned in the same identity to the correct list than words learned in the other identity. This pattern of results was also shown, but to a lesser degree, by simulators. Patients and simulators were more conservative in list A recognition and assigning words to list A compared to list B, i.e., they were inclined to assign words recognized to the list learned in the same identity state, irrespective of the origin of the word. Again, however, these patterns in list assignment were not specific for negatively valenced words. Finally, we found no significant differences in remember and know responses in recognition between words learned in the same vs. another identity state. This indicates that patients did not experience recognizing material learned in the same identity any differently compared to material learned in another identity state.

In sum, we thus conclude that we did not find evidence of total interidentity amnesia specifically for negative words. Patients were able to consciously retrieve information learned by another identity. Recently, one other study was performed with DID patients that included words that had a threatening or sexual connotation. Elzinga, Phaf, Ardon, and Van Dyck $(2003 ; n=12)$ used a directed forgetting paradigm to investigate intentional forgetting in DID. No control participants were included. In line with the results of the present study, the prediction that recall of negative words would be reduced compared to neutral words was not confirmed. The mean recall was even in the opposite direction, with more negative than neutral words being recalled. In the present study, participants were also found to overall recall more negative words compared to neutral and positive words. This, however, was true for patients as well as normal controls and simulators.

While thus not finding evidence of material-selective interidentity amnesia, the patients' overall superior list $\mathrm{B}$ recognition and assignment, that is, independent of stimulus valence, might perhaps be taken as an indicator for partial interidentity amnesia. However, this conclusion can strongly be doubted because of the simulators' ability to simulate this performance. Furthermore, the results of higher list B recognition sensitivity and assignment for patients and simulators were not found in our previous experiment of interidentity amnesia (with samples partially overlapping between experiments), in which only neutral stimuli were included (Huntjens et al., 2003). The procedures of both experiments differed in the interval used between the study and test phase. In the experiment with neutral material, an interval of a week was used between trials, while in the procedure reported here, this interval was shortened to $2 \mathrm{~h}$ for practical reasons. In our previous experiment, the results indicated simulators were not able to simulate interidentity amnesia, that is, no differences in list performance were found between simulators and normal controls. The different behavior of simulators in both experiments can be explained by the interval between the learning and test trial. It may be easier to keep highly similar material apart shortly after encoding than after a while. Patients also did not differ from normal controls (and simulators) in list performance in our previous experiment. As no differences were found between simulators, normal controls, and patients in the previous experiment, the conclusion was drawn that no evidence of interidentity amnesia was found and patients were characterized by transfer of (neutral) information between identities. In our previous experiment simulation proved impossible. The results indicated no evidence of interidentity amnesia for neutral stimulus material. We therefore conclude in the present experiment, where partial simulation of amnesia did prove possible, the patient results of better overall list B performance compared to list A performance (overall, but not specifically for negative stimulus material) should not be taken as evidence of partial interidentity amnesia.

A word is needed on the memory processes involved in the present experiment. Nissen et al. (1988) noted that the terms implicit and explicit can be used in different ways in studying DID. Typically, the terms are used as labels for types of memory tests, such that if a test requires conscious remembering it is an explicit memory test (e.g., free recall and recognition), and if it does not it is an implicit test (e.g., repetition priming). In studying DID, explicit tests can also allow the implicit expression of knowledge acquired by other identities than the one being tested. For example, the learning of a list of words might be enhanced by the previous presentation of the same words to a different identity, while the patient might be unaware another identity was presented with the material. With regard to the intrusion and recognition measures in the present experiment, patients explicitly named, however, material learned by another identity. They were able to directly and consciously retrieve the material. The measures employed are thus regarded as explicit memory measures, and 
the results of transfer between identities as an indication of an ability to consciously retrieve material learned in another identity state. After retrieval then, the material was assigned (relatively often) to list B, i.e., patients responded as if the material was learned in the same identity state. The conservative list A assignment response bias for patients and simulators was also found in our previous experiment including neutral stimulus material. Although they did recognize words from the list learned by the other identity, they relatively rarely assigned them to that list. Both groups showed an inclination to assign words to their "own" list. This pattern of results is not specific for negatively valenced material.

As in our previous experiment on neutral stimulus material, the patients' memory performance did differ from normal controls and simulators in that they overall recalled less words and they scored significantly lower on overall recognition sensitivity, i.e, the ability to distinguish "old" words from "new" words in recognition. An overall impaired memory performance is often found in other psychiatric disorders, notably anxiety disorders like PTSD (Bremner et al., 1993) and depression. Patients with these disorders have been suggested to have diminished processing resources available for memory tasks due to emotional preoccupation (Baddeley, Wilson, \& Watts, 1995), resulting in a diminished test performance.

Patients were found to resemble simulators on a number of measures in this experiment, most noticeable in reduced recall of words learned in their amnesic identity, enhanced recognition of words learned in the same identity state compared to words learned in the other identity state, and a conservative assignment bias to the list presented to the other identity. While simulators were instructed to simulate interidentity amnesia, they were not instructed to perform worse in recall in their amnesic identity. Their decreased recall score in their amnesic identity may have been due to them spending attention and effort to playing their role of DID patient. We do not want to contend, however, that the resembling performance of patients and simulators in this experiment - or indeed in other studies of DID including simulators - implies that patients are deliberately simulating their condition. It is equally possible that patients may be truly convinced of their inability to retrieve material learned in another identity. The issue should be explored in future research by carefully debriefing patients and simulators on their thoughts and efforts during testing.

Taken together, the results of this experiment, which investigated retrieval of emotionally valenced material, and our previous experiment, which investigated retrieval of neutral material, indicate transfer of information between identities in DID. These findings strikingly contrast with the patients' subjective reports of total amnesia for the task performed and material learned by the learning identity. The experiments reported should not be regarded as completely independent evidence, given the partial patient overlap. The results presented here collude, however, with the results of Allen and Movius (2000) and Silberman, Putnam, Weingartner, Braun, and Post (1985). We thus want to argue that DID might not be characterized by "objective" interidentity amnesia. Patients might have the ability to retrieve information learned in another identity state, both for neutral stimulus material and emotionally valenced information. Notwithstanding the need for additional studies including independent, large patient samples, the findings of the present study may have important implications for the conceptualization of DID in the future. Dissociative amnesia in DID may more adequately be described in the $D S M$ as a disturbance in meta-memory functioning, with meta-memory referring to knowledge, beliefs, and feelings about memory (Dixon, 1989). It may be that patients, because they experience themselves as "consisting" of multiple identities, are convinced of their memories being compartmentalized in separate identities (see also Allen \& Iacono, 2001). In support of this view, a recent study in a subclinical normal population found evidence for perceived memory fragmentation (i.e., metamemory) but not objective memory fragmentation in high compared to low dissociators (Kindt \& Van den Hout, 2003). Dissociators thus seem to be characterized by the belief of being unable to recall information instead of an actual retrieval inability.

\section{Acknowledgements}

Albert Postma was supported by a grant from the Netherlands Organization for Fundamental Research (NWO, No. 440-20-000). We thank Rob Broekmans, Rivka van den Bergh, and Diane Pecher for their help in designing the study. We especially thank the patients who participated in the study and the clinicians for their help in gathering the patient sample and for their assistance in testing. 


\section{References}

Allen, J. B., \& Iacono, W. G. (2001). Assessing the validity of amnesia in dissociative identity disorder: A dilemma for the DSM and the courts. Psychology, Public Policy, and Law, 7, 311-344.

Allen, J. B., \& Movius, H. L. (2000). The objective assessment of amnesia in dissociative identity disorder using event-related potentials International Journal of Psychophysiology, 38, 21-41.

American Psychiatric Association. (1994). Diagnostic and statistical manual of mental disorders (4th ed.). Washington, DC: Author.

Baddeley, A. D., Wilson, B. A., \& Watts, F. N. (1995). Handbook of memory disorders. Chichester, England: Wiley.

Boon, S., \& Draijer, N. (1993). Multiple personality disorder in the Netherlands: A study on reliability and validity of the diagnosis. Lisse, The Netherlands: Swets \& Zeitlinger.

Bradley, M. M., Greenwald, M. K., Petry, M. C., \& Lang, P. J. (1992). Remembering pictures: Pleasure and arousal in memory. Journal of Experimental Psychology: Learning, Memory, and Cognition, 18, 379-390.

Bremner, J. D., Scott, T. M., Delaney, R. C., Southwick, S. M., Mason, J. W., Johnson, D. R., et al. (1993). Deficits in short-term memory in posttraumatic stress disorder. American Journal of Psychiatry, 150, 1015-1019.

Cardeña, E. (1994). The domain of dissociation. In S. J. Lynn, \& J. W. Rhue (Eds.), Dissociation: Clinical and theoretical perspectives (pp. 15-310). New York: Guilford.

Cardeña, E. (2000). Dissociative disorders. In A. E. Kazdin (Ed.), Encyclopedia of psychology (pp. 55-59). Oxford: Oxford University Press.

Carlson, E. B., \& Putnam, F. W. (1993). An update on the Dissociative Experiences Scale. Dissociation, 6, 16-27.

CELEX. (1990). On-line Dutch database (Release N31). Nijmegen, The Netherlands: Centre for Lexical information.

Dick-Barnes, M., Nelson, R. O., \& Aine, C. J. (1987). Behavioral measures of multiple personality: The case of Margaret. Journal of Behavioral Therapy and Experimental Psychiatry, 18, 229-239.

Dixon, R. A. (1989). Questionnaire research on metamory and aging: Issues of structure and function. In L. W. Poon, D. C. Rubin, \& B. A. Wilson (Eds.), Everyday cognition in adulthood and late life (pp. 394-415). Cambridge, UK: Cambridge University Press.

Dorahy, M. J. (2001). Dissociative identity disorder and memory dysfunction: The current state of experimental research, and its future directions. Clinical Psychology Review, 21, 771-795.

Eich, E., Macaulay, D., Loewenstein, R. J., \& Dihle, P. H. (1997a). Memory, amnesia, and dissociative identity disorder. Psychological Science, 8, 417-422.

Eich, E., Macaulay, D., Loewenstein, R. J., \& Dihle, P. H. (1997b). Implicit memory, interpersonality amnesia, and dissociative identity disorder: Comparing patients with simulators. In J. D. Read, \& D. S. Lindsay (Eds.), Recollections of trauma: Scientific research and clinical practice (pp. 469-474). New York: Plenum Press.

Elzinga, B. M., Phaf, R. H., Ardon, A. M., \& Van Dyck, R. (2003). Directed forgetting between, but not within, dissociative personality states. Journal of Abnormal Psychology, 112, 237-243.

Erdfelder, E., Faul, F., \& Buchner, A. (1996). GPOWER: A general power analysis program. Behavior Research Methods, Instruments, \& Computers, 28, 1-11.

Gardiner, J. M. (1988). Functional aspects of recollective experience. Memory \& Cognition, 16, 309-313.

Gardiner, J. M., \& Java, R. I. (1993). Recognition memory and awareness: An experimental approach. European Journal of Cognitive Psychology, 5, 337-346.

Gardiner, J. M., \& Parkin, A. J. (1990). Attention and recollective experience in recognition memory. Memory \& Cognition, 18, 579-583.

Hermans, D., \& De Houwer, J. (1994). Affective and subjective familiarity ratings of 740 Dutch words. Psychologica Belgica, 34, 115-139.

Huntjens, R. J. C., Postma, A., Hamaker, E. L., Woertman, L., Van der Hart, O., \& Peters, M. (2002). Perceptual and conceptual priming in patients with dissociative identity disorder. Memory \& Cognition, 30, 1033-1043.

Huntjens, R. J. C., Postma, A., Peters, M., Woertman, L., Effting, M., \& Van der Hart, O. (2005). Transfer of newly acquired stimulus valence between identities in dissocative identity disorder. Behaviour Research and Therapy, 43, 243-255.

Huntjens, R. J. C., Postma, A., Peters, M., Woertman, L., \& Van der Hart, O. (2003). Interidentity amnesia for neutral, episodic information in Dissociative Identity Disorder. Journal of Abnormal Psychology, 112, 290-297.

Kindt, M., \& Van den Hout, M. (2003). Dissociation and memory fragmentation: Experimental effects on meta-memory but not on actual memory performance. Behaviour Research and Therapy, 41, 167-178.

Knowlton, B. J. (1998). The relationship between remembering and knowing: A cognitive neuroscience perspective. Acta Psychologica, 98 , 253-265.

Knowlton, B. J., \& Squire, L. R. (1995). Remembering and knowing: Two different expressions of declarative memory. Journal of Experimental Psychology: Learning, Memory, and Cognition, 21, 699-710.

Lewis, D. O., Yeager, C. A., Swica, Y., Pincus, J. H., \& Lewis, M. (1997). Objective documentation of child abuse and dissociation in 12 murderers with dissociative identity disorder. American Journal of Psychiatry, 154, 1703-1710.

Lilienfeld, S. O., Lynn, S. J., Kirsch, I., Chaves, J. F., Sarbin, T. R., Ganaway, G. K., et al. (1999). Dissociative identity disorder and the sociocognitive model: Recalling the lessons of the past. Psychological Bulletin, 125, 507-523.

Ludwig, A. M., Brandsma, J. M., Wilbur, C. B., Benfeldt, F., \& Jameson, D. H. (1972). The objective study of a multiple personality. Archives of General Psychiatry, 26, 298-310.

Macmillan, N. A., \& Creelman, C. D. (1991). Detection theory: A user's guide. Cambridge, England: Cambridge University Press.

Merckelbach, H., Rassin, E., \& Muris, P. (2000). Dissociation, schizotypy, and fantasy proneness in undergraduate students. Journal of Nervous and Mental Disease, 188, 428-431. 
Nissen, M. J., Ross, J. L., Willingham, D. B., Mackenzie, T. B., \& Schacter, D. L. (1988). Memory and awareness in a patient with multiple personality disorder. Brain and Cognition, 8, 117-134.

Ogawa, J. R., Sroufe, L. A., Weinfield, N. S., Carlson, E. A., \& Egeland, B. (1997). Development and the fragmented self: Longitudinal study of dissociative symptomatology in a nonclinical sample. Development and Psychopathology, 9, 855-879.

Peters, M. L., Uyterlinde, S. A., Consemulder, J., \& Van der Hart, O. (1998). Apparent amnesia on experimental memory tests in dissociative identity order: An exploratory study. Consciousness and Cognition, 7, 27-41.

Postma, A. (1999). The influence of decision criteria upon remembering and knowing in recognition memory. Acta Psychologica, 103, 65-76.

Putnam, F. W. (1995). Development of dissociative disorders. In D. Cicchetti, \& J. Cohen (Eds.), Developmental psychopathology (pp. 581-608). New York: Wiley.

Putnam, F. W., Guroff, J. J., Silberman, E. K., Barban, E. K., \& Post, R. M. (1986). The clinical phenomenology of multiple personality disorder: 100 recent cases. Journal of Clinical Psychiatry, 47, 285-293.

Silberman, E. K., Putnam, F. W., Weingartner, H., Braun, B. G., \& Post, R. M. (1985). Dissociative states in multiple personality disorder: A quantitative study. Psychiatry Research, 15, 253-260.

Spanos, N. P. (1996). Multiple identities \& false memories. A sociocognitive perspective. Washington, DC: American Psychological Association.

Steinberg, M. M. D. (1993). Structured Clinical Interview for DSM-IV Dissociative Disorders (SCID-D). Washington, DC: American Psychiatric Press.

Stevens, J. (1996). Applied multivariate statistics for the social sciences. Mahwah, NJ: Lawrence Erlbaum Associates.

Tulving, E. (1985). Memory and consciousness. Canadian Psychologist, 26, 1-12.

Verhage, F. (1964). Intelligentie en leeftijd: Onderzoek bij Nederlanders van twaalf tot zevenenzeventig jaar [Intelligence and age: Study with Dutch people from age 12 to 77]. Assen, The Netherlands: Van Gorcum. 